\title{
Reliability Indices of a combined PV, Wind and Grid System
}

\author{
K Lokeswara Rao ${ }^{1}$, Phanidhar $S \mathrm{~V}^{2}$ \\ ${ }^{1}$ Assistant Professor, EEE Dept, GITAM School of Technology, KA, India. 1ksheera@ gitam.edu \\ ${ }^{2}$ Assistant Professor, EEE Dept, GITAM School of Technology, KA, India. psudani@ gitam.edu
}

\begin{abstract}
Renewable energy extracted from the sources like sunlight, wind, sea tides, waves, and geothermal many more. These methods benefits to subsidies the global warming consequences. It benefits to improve the security of existing power scheme. But the renewable energy sources are uncertain in nature. To find a solution for these uncertainties, there are some contingency existing methods are available. In these arrangements, detailed arrangements have greater advantages. One of the existing detailed arrangements is the FLM (Failure of Load method). There are different security indices each index has its own contribution to improve the power scheme Security.

The Capacity Blackout Contingency Table (CBCT) and the Load Extent Curves (LEC) arrangements are using to evaluate power scheme indices in terms of the power scheme security including $\mathrm{PV}$ and wind $\mathrm{RE}$ schemes each has its specific Forced Blockout Rate (FBR). The intention of the recommended work is to develop PV interconnected and wind energy schemes along with the existing power scheme grid to improve its security indices by collecting required information from the load extent curves. MATLAB Program/SIMULINK blocks have been developed and the obtained results are analyzed on a sample power scheme network, and the results are analyzed.
\end{abstract}

Key words: Security in Power Generating Scheme assessment, FLM-Failure of Load method, Wind Scheme, Solar PV Power, Security indices.

\section{INTRODUCTION}

Power is the main source in our day to day activities to lead our life comfortable it is also one of the crucial factors of any country's growth interims of economics [1]. The load demand acting on existing power generation is continuously varies due to consumer behavior based on seasonal changes. To meet this continuous load changes the generating stations are ready to take the load variation at all the time without losing the power quality aspects such as Voltage, phase angle, frequency, and other parameters. At any point in time if the consumer disconnected from the supply it leads to loss of income to both the parties' i.e generating stations and the small, larges scale production industries. To overcome this dynamic behavior of both the PV \& wind scheme operates efficiently.

In the early days, the security of the power scheme can be improved by identifying the occurrence of disturbances with the benefit of various available deterministic arrangements. A single instant failure does not affect the performance of the entire scheme. These arrangements don't give any information on the contingency of occurrences of single scheme failure. The influence of the power scheme considered during its failures for the assessment of the performance of power scheme network interns of its security in different approaches of procedures without power failure [2],[3]. The existing arrangement impacts scheme accuracy and power failures due to the dynamic behavior of Renewable sources compared to conventional sources. Due to its dynamic behavior of the RE schemes, the scheme accuracy and performance of the scheme is poor than conventional sources. The main intention is to improve security by introducing RE schemes sensing and evaluating data collected from the LEC curve \&CBCT table. In this recommended work, the existing power scheme network security improved by operating RE schemes efficiently without interrupting existing network performance.

In the recommended scheme 200 solar panels of $810 \mathrm{~W}$ capacity are considered rather than 50 panels having a $28 \%$ capacity factor along with 35 Numbers of wind turbines with a capacity of $2 \mathrm{MW}$ rather than 20 Numbers of wind turbines with a $50.6 \%$ capacity factor [4],[5].

The security of the existing power scheme network including RE schemes can be assessed with the benefit of available various detailed arrangements. The set of available security indices for power scheme analysis are as below:

(a) FOLC - Failure of Load Contingency

(b) FOLP - Failure of Load Prediction

(c) RENS - Required Energy Not Supplied

To evaluate the power scheme security indices with the benefit of data available in the LDS curves and CBCT table. These indices used to extract a point of scheme accuracy including RE schemes with specific Forced Blockout Rate (FBR) [6].

\section{GENERATION CONTINGENCYARRANGEMENT}

The power scheme is an interconnection of different generating plants with transmission and distribution schemes connected to loads to meet the required load demand without losing continuity of power supply [9],[10],[11]. With the 
benefit of detailed arrangement power schemes including RE sources are assessed. The security scheme indices benefit in meeting the required load demand by operating available generating units at that instant.

During excess power production or less load demand on generating stations due to the availability of resources, power outages cannot occur. The required power generating can be obtained by CBCT; it gives the contingency of a shortage of power or power loss due to excess load demand occurrence. The load model is introduced by the LEC. This can be obtained by noting or monitoring hourly load demand. The FBR of generating unit, is represented by $U$ it is the unit contingency in the mandatory outage stage or unapproachable stage. The FBR can be calculated as follows [12].

$$
\begin{aligned}
& \text { FOR }=U=\frac{\sum T_{\text {down }}}{\sum T_{\text {up }}+\sum T_{\text {dow } n}}=\frac{\lambda}{\lambda+\mu} \\
& P_{\text {up }}=\frac{\mu}{\lambda+\mu} \\
& P_{\text {down }}=\frac{\lambda}{\lambda+\mu}
\end{aligned}
$$

Where,

$\lambda$ is a rate of scheme failure, $\mu$ is a repair rate of a generating unit, $\mathrm{P}_{\mu \mathrm{p}}$ is the contingency of per-unit generator upstate, and $P_{\text {down }}$ is the contingency of per-unit generator downstate. $T_{\mu p}$ and $\mathrm{T}_{\text {down }}$ denote the operating time of the generating units and also in the failure time.

\section{FAILURE OF LOADARRANGEMENT ALGORITHM - AN DETAILEDARRANGEMENT}

Generating unit without fail within the considered time extent $(t)$ is known as security. With this power scheme security is denoted as:

$R(t)=P(T>t)$

Where, $\mathrm{T}$ is the time of failure power scheme. The contingency of total unreliable scheme given by

$F(t)=1-R(t)=P(T<t)$

Failure of Load is a more popular detailed arrangement considered in this paper for the implements in the scheme. This capacity of generating units is considered from CBCT table. With the benefit of this arrangement security of the existing power scheme with RE scheme has been improved. From the recommended arrangement each generation scheme is represented by two state models implemented with the help of Markov arrangement. The systematic model benefits in evaluating scheme accuracy indices like FOLC, FOLP, and RENS, which can be assessed from state models.

The power lost instance information in hours can be identified by considering the FOL index in the given time interval, where the maximum power demand in hours more than the generating capacity at that instance.

The FOLC can be expressed as:

$F O L C=\sum_{i=1}^{n}\left(p_{i} * t_{i}\right)\left(L_{\max }>C\right)(h / y r)$

where,

$\mathrm{n}$ is the period of instant considered in days (hours), $\mathrm{p}_{\mathrm{i}}$ possibility of $i_{\text {th }}$ instance of outage obtained from the CBCT table, and $t_{i}$ no. of times the generating unit lost and causes power outages. Reserve capacity is the excess power readily available to meet the sudden increase in load demand which can benefit to take up the increased load demand immediately and improves the security of the scheme.

These days, the FOLC index can't use consistently due to its specific scheme failure. The FOLC index represented by the equation

$F O L C=\sum_{i=1}^{n}\left(p_{i}\right)\left(L_{\text {max }}>C\right)$

The Figure 1 shows the flow chart which explains the algorithm in a sequential manner, used to calculate the Failure of Load Contingency (FOLC) index that identifies information on the security index in the power scheme implementation in order to determine the additional required power for the upcoming year in the process of planning. The required level of FOLP that imposes the service organization denoted as FOLP .

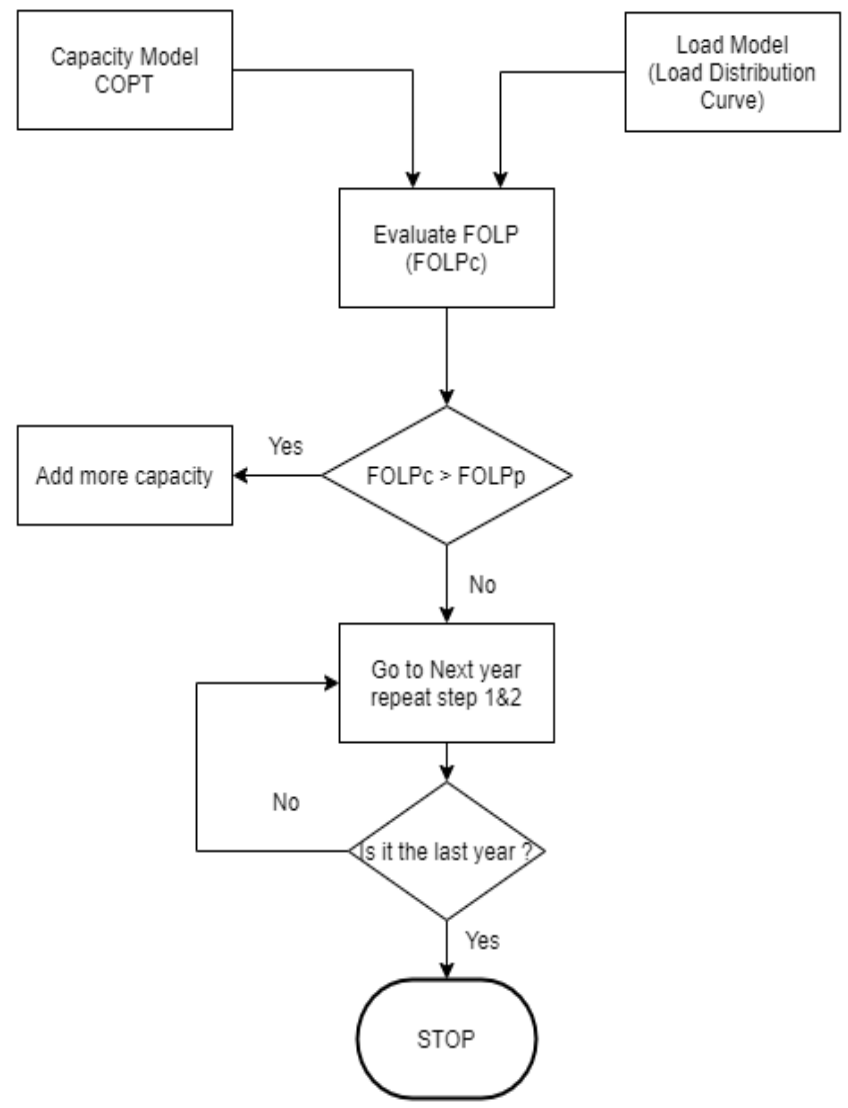

Figure 1: Algorithm sequential manner, used to calculate the Failure of Load Prediction (FOLP) index

In these days FOLP indexing analysis not used to find security of the scheme with RE sources because of its more contingency in identifying scheme failure duration (in hours). The FOLP index estimated with the help of equation.

$F O L P=\sum_{i=1}^{n}\left(p_{i}\right)\left(L_{\max }>C\right)$

The major intention of all the A first and foremost intentions of the service organizations is demand in energy followed by a power scheme security index is RENS i.e required energy demand not met. The RENS will be given as 
K Lokeswara Rao et al., International Journal of Emerging Trends in Engineering Research, 8(9), September 2020, 5238 - 5241

below it is given

$R E N S=\sum_{i=1}^{n}\left(E N S_{i} * p_{i}\right)\left(L_{\max }>C\right)(M W h / y r)$

\section{ESTIMATION OF PROPSED SCHEMEWITH SOLAR AND WIND}

Table 1 shows Roy Billinton Test Scheme (RBTS) is considered in evaluation process of power scheme [7],[8] . Figure 2 shows the single line diagram for the RBTS. The recommended power scheme consists of 6 Bus with a different rating of the generator

(i) 5 Buses are loaded out of available 6 Buses,

(ii) Interconnected lines are 9, and

(iii) At Bus-1 2 units of 40MW, 1 Unit 20MW and 1 Unit 10MW and at Bus-2 1 Unit 40MW, 4 Units of $20 \mathrm{MW}$ and 2 Units of $5 \mathrm{MW}$ are considered.

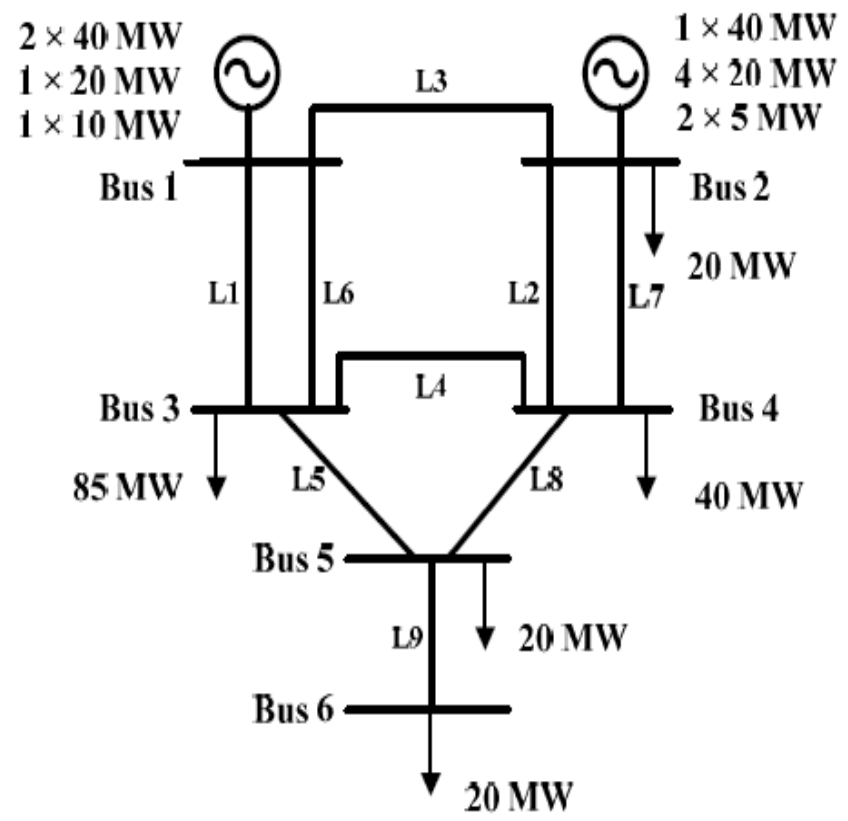

Figure 2: RBTS Single line diagram

For case (I):consider power scheme with RE scheme with a capacity of $80.5 \mathrm{MW}$ to the RBTS with $4 \%$ FRO.

Wind System $\rightarrow 20$ wind forms of each $2 \mathrm{MW}$ total of $40 \mathrm{MW}$

PV system $\rightarrow 50$ panels of each $810 \mathrm{~W}$ total of $40.5 \mathrm{MW}$

For case (II):Including steam units with a capacity of 80.5 MW interfaced with the RBTS scheme. The FBR was $4 \%$. Steam unit $\rightarrow 2$ Units of each $40.25 \mathrm{MW}$ total of $80.5 \mathrm{MW}$

Table 1: RBTS Security Data for Conventional Generation Unit

\begin{tabular}{|c|c|c|c|c|c|}
\hline $\begin{array}{c}\text { Size } \\
(\mathbf{M W})\end{array}$ & $\begin{array}{c}\text { Type of } \\
\text { Unit }\end{array}$ & $\begin{array}{c}\text { No of } \\
\text { Units }\end{array}$ & FBR & MTTF/h & MTTR/h \\
\hline 5 & Hydro & 2 & 0.010 & 4380 & 45 \\
\hline 10 & Thermal & 1 & 0.020 & 2190 & 45 \\
\hline 20 & Hydro & 4 & 0.015 & 3650 & 55 \\
\hline 20 & Thermal & 1 & 0.025 & 1752 & 45 \\
\hline 40 & Hydro & 1 & 0.020 & 2920 & 60 \\
\hline 40 & Thermal & 2 & 0.030 & 1460 & 45 \\
\hline
\end{tabular}

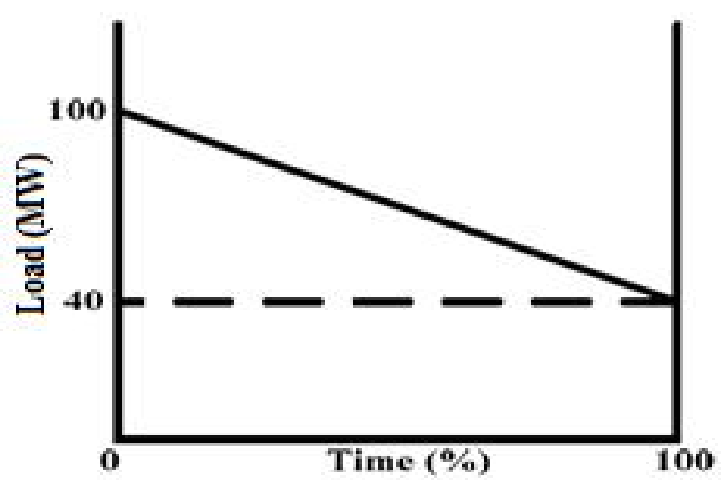

Figure 3: Load model of the scheme

In this investigation, the hourly planned load distribution considered by the load extent curve (LEC). Here, we assume a linear line load model with a $100-40 \%$ change in load depending on peak load demand during two conduction of test on both cases. The LEC load model is thoroughly designed with the benefit of hourly data.

According to NREL i.e., the Transparent Cost Database of the National Renewable Energy Laboratory, under examination of any sunlight radiation and sudden changes in wind speed variations with a capacity factor of $50.6 \%$ and $28 \%$ respectively. Therefore, the capacity value of the one-unit wind turbine considered the capacity factor is $1.012 \mathrm{MW}$ and also the capacity value of one unit PV array considering the capacity factor is $0.2268 \mathrm{MW}$.

Wind source of $\cdot 35$ Units * 2MW each * 0.506total of35.22 MW

Solar source of 200 panels of $810 \mathrm{~W}$ each $* 0.28$ total of45.28 MW

Power produced by both wind $35.22 \mathrm{MW}$ and solar system 45.28MW is $80.5 \mathrm{MW}$.

Table 2:Evaluating RENS and FOLC for all possible Cases with recommended scheme

\begin{tabular}{|c|c|c|c|c|}
\hline $\begin{array}{c}\text { Security } \\
\text { indices }\end{array}$ & $\begin{array}{c}\text { RBTS } \\
\text { Base } \\
\text { case }\end{array}$ & Case I & Case II & $\begin{array}{c}\text { Recommended } \\
\text { Scheme }\end{array}$ \\
\hline $\begin{array}{c}\text { FOLP } \\
\text { (h/yr) }\end{array}$ & 11.4879 & 0.6201 & 0.4341 & 0.3944 \\
\hline $\begin{array}{c}\text { RENS } \\
(\mathrm{MWh} / \mathrm{yr})\end{array}$ & 116.817 & 5.6201 & 4.6657 & 4.2416 \\
\hline
\end{tabular}

Finally, the recommended analysis justifies that the security of the power scheme was enhanced imperatively with the help of renewable energy sources and also it benefits the power scheme planners while high petrifying of grid-inter connected renewable energy sources are considered.

\section{CONCLUSION}

In this recommended work, the extensive power scheme loyalty using solar and wind along with other forms of power production can be calculated and studied with the benefit of FOL arrangement. The power scheme accuracy will be 
assessing and investigate the security scheme indices. Both LLE and RENS benefit in identifying and finding solutions improvements in power scheme security.

The observed results are interpreting by developing MATLAB code for unlike instances by seeing the CBCT table and LEC curve data. It also supports and provides necessary power up to its maximum capacity factor including $\mathrm{RE}$ sources. Finally, the purposed analysis approves the security of the entire scheme improved automatically by the usage of $\mathrm{RE}$ sources it benefitful for power scheme planners.

\section{REFERENCES}

1. Amir Ahadi ; Syed Enam Reza ; Xiaodong Liang Probabilistic security evaluation for power schemes with high penetration of renewable power generation2017 IEEE/IAS 53rd Industrial and Commercial Power schemes Technical Conference (I\&CPS) 2017.

2. A. Kumar, Shivani Sehgal, A. Deepika, A. Soni Capacity Outage Probability Table Calculation (Copt) of Haryana Power Generation Corporation Limited Using VBA, 2013IJTR.

3. A. Almutairi, M. H. Ahmed and M. M. A. Salama Inclusion of wind generation modeling into the conventional generation adequacy evaluation, 2014EPEC, IEEE.

4. Transparent Cost Database from NREL. Check from: http://en.openei.org/apps/TCDB/\#blank.

5. C. S. R. Atla and K. Balaraman Generation planning with intermittent renewable energy sources using probabilistic methods, 2012ICPCES.

6. Roy Billinton and Guang Bai Generating capacity adequacy $\mathbf{y}$ associated with wind energy, 2004 IEEE transactions.

7. R. Karki, Po Hu and Roy BillintonA simplified wind power generation model for security evaluation,2006 IEEE transactions.

8. COPT Table Calculation. Check from: faculty.ksu.edu.sa/shaalan/Documents/L(09).pdf.

9. R. Karki and Roy Billinton The Security/cost implications of PV and wind energy utilization in small isolated power schemes2001IEEE transactions.

10. Vestas Wind Schemes. Check from website link https://www.vestas.com.

11. K Lokeswara Rao , SLV Sravan Kumar Power Quality Enhancement of Grid Integrated Distribution Scheme with Renewable Energy Sources IJETER Volume 8. No. 8, 4607-4612, August 2020.

12. Ramprasad Vangalapudi, Dr. K.Ravikanth Wind Power Influence on the Small Signal Stability of Grid Integrated Distribution Schemes IJETER Volume 8 No. 73569 - 3574, July 2020. 